This is a peer-reviewed, accepted author manuscript of the following research article: Farmer, J., Taylor, J., Stewart, E., \& Kenny, A. (2017). Citizen participation in health services co-production: a roadmap for navigating participation types and outcomes. Australian Journal of Primary Health, 23(6), 509

515. https://doi.org/10.1071/PY16133\#sthash.qzOb7bnH.dpuf

\title{
Citizen participation in health services co-production: a roadmap for navigating
} participation types and outcomes

\begin{abstract}
Primary healthcare managers are required to include citizens in service codesign and co-production. Health policy guidance appears deceptively simple and largely outlines how people could participate in a range of health services activities. It tends to neglect outcomes assessment, while a multi-disciplinary academic literature is large and complex to navigate for practical, time-poor managers. In this paper we set out to provide a summary 'map' of key concepts in participation to assist managers in aligning participants, activities, expected outcomes, outcome indicators; and to consider contextual factors that could affect participation processes and outcomes. The intention is a practical tool for planning and evaluation of participation. The map is built drawing on policy guidance, literature and authors' experiences of implementing and researching health services participation.
\end{abstract}

Jane Farmer, Swinburne University, John Street, Hawthorn, Melbourne, Australia, 3122 jcfarmer@swin.edu.au

Judy Taylor, James Cook University, Townsville, Queensland, Australia, 4811 judy.taylor@jcu.edu.au

Ellen Stewart, Usher Institute, University of Edinburgh, Edinburgh, Scotland EH16 4UX e.stewart@ed.ac.uk

Amanda Kenny, La Trobe University. Edwards Road, Bendigo, Victoria, Australia, 3550 a.kenny@latrobe.edu.au 


\section{Summary Statement}

\section{What is known about this topic?}

There is a considerable literature on participation in health services co-production, but a tendency to imprecision in defining activities and outcomes which makes planning and evaluating participation activities confusing and inconsistent.

\section{What does this paper add?}

We delineate key categories and concepts within participation and align participants, activities, outcomes and measures, thus providing a frame for consistency in future participation planning and evaluation. 


\section{Citizen participation in health services co-production: a roadmap for navigating participation types and outcomes}

"public engagement has become a fundamental feature of the public-government relationship" (Quick and Feldman, 2011, p.272)

In Australia and elsewhere, managers responsible for commissioning and providing primary healthcare are required to facilitate the participation of lay participants - that is, consumers, the public and/or communities in aspects of service design and delivery (Keleher, 2015; McEvoy \& McFarlane, 2013). Since the 1960s, in health services, a 'family' of terms has been applied to discuss the broad topic of participation by lay people in service decision-making and other activities (Stewart, 2016; p.8). Taken together this reflects a general policy turn to participation (Holman, 2014). Contemporaneously, while some levels of discussion still focus on debates on whether citizens should have influence or merely be consulted (Australian Government, 2015), some guidance in Australia refers actively to 'partnering' with lay people (Australian Commission on Safety \& Quality in Health Care (ACSQHC), 2012). Partnering implies equivalence with health managers and practitioners in activities.

In our studies over more than a decade in different developed countries and cultures, we have found an apparent degree of confusion over what participation is for, and how to do it, in health services literature and among healthcare managers. Indeed, we have found repeated instances of managers implementing participation initiatives because policy tells them to, rather than with a defined purpose and having considered desired outcomes. We argue this is partly because policy is sketchy and academic literature is dense - often considering challenges and complexities rather than providing managers with accessible, entry-points to planning, action and evaluation. 
Thus, in this article, we seek to provide an accessible 'roadmap' for managers, helping them to navigate and interrogate participation activities. The article is not intended to be definitive about citizen participation in health - directing managers towards a 'true' or 'real' participation - rather to be a short, easy-to-use overview which demonstrates the range of purposes and approaches. It is intended to summarise key dimensions, particularly focused on aspects of instrumental (i.e. top-down) (Taylor, 2015; pp.114-117) service codesign and co-production; taking a healthcare managers' perspective. The map is intended to help managers to understand, and perhaps discuss and probe, the policy directions they receive, and then to plan activities appropriately.

Scholars from many social science disciplines - including sociology, management studies, geography and political science - have researched and discussed participation processes, often with particular interests aligned to key disciplinary concerns (for example, an interest in power is a recurring theme within political science accounts). This paper seeks to take an over-arching view of this landscape, and specifically to guide managers who are tasked with implementing these practices within organisations. Literature tends to discuss participation and related terms - involvement, engagement and partnership as though there is a shared understanding and underlying theory. While there is a broad policy story around participation (Holman, 2014), there are differences implied in varying terms and sometimes underlying political messaging (Stewart, 2016; p.12). We contend there is a lack of a shared theory of participation in contemporary developed-country health services co-production. The situation remains, as Contandriopoulos (2004) highlighted - that 'public participation is only that indistinct and undefined part of normal political and administrative behaviours we are used to calling that way'. 
Discussions of participation sometimes commence from a 'them versus us' position and consider the relative power of 'lay' participants in relation to managers, technical or professional elites - Arnstein's (1969) 'ladder' of participation classically underpins that genre. A stream of writing applies participation in distinct (normatively understood as marginalised and un-empowered) cultural/geographical settings. The work of Rifkin (e.g. 2014 ) is central in that genre, with participation employed as a social process with anticipated effects of increases in individual and community empowerment, capacity and health literacy. Some guidance implies an understanding of participation where diverse marginalised people are 'invited in' to the decision-making spaces offered by technical elites - although staff groups are requested to consider appropriate ways to do this (ACSQHC, 2012; p.13). More cutting-edge perspectives portray stakeholders as not dichotomously divided into lay and expert/technical, but rather highly diverse, multifaceted; and with extended goals beyond mere opinion-giving to roles in local problemsolving and community governance (Meads et al., 2016).

In this article, participation is depicted as a type of intervention. This is because managers are asked by policymakers to 'do participation' which essentially requires an instrumental approach; 'applying' participation as a means to an end (Taylor, 2015; pp.114-117). Here, we set out to help managers identify: the target group to involve, the activities to involve them in, the potential intended outcome, and potential outcome indicators. We also provide some commentary on intervening (contextual) factors that could affect participation. The role of this map is to help managers to delineate their participation activities, to consider the outcomes they want to achieve and to identify ways that these 
outcomes might be assessed. We propose this to encourage clearer thinking around participation activities.

In health policy, participation is implied/presumed to produce beneficial outcomes, but capturing these is not routinised (Attree et al., 2011). Tolerance of this seems curious with such emphasis in healthcare on evidence and performance (Preston et al., 2010). Here, with our disentangling of diverse literature and policy messages, we potentially pave the way for more consistent assessment of outcomes of instrumental participation. Our map responds to calls to analyse participation in order to better understand and improve it (Preston et al., 2010; George et al., 2015). In proposing this first attempt at a conceptual map, we invite others to use, refine and develop the map.

\section{Positioning this paper}

This article was designed as a short and accessible guide for managers and practitioners, and is not a systematic review of the literature. Following the columns in Figure 1, we delineate options within key fields that managers should specify when designing a participation activity to help align activities with outcomes that can be measured. We include coverage of: target group, intended outcome, activity, outcome indicators and intervening (contextual) factors that could affect what happens. To identify an initial structure, we scanned Australian health agency guidance (principally, ACSQHC, 2012 and Primary Health Network (PHN) guidance (e.g. Australian Government, 2015)). This provided an initial 'map' showing the participant and activity categories that managers were asked to address. We then drew on health services and literature from other disciplines, where we deemed that relevant and insightful, to verify and extend these categories. As noted, our perspective here is influenced by the positionalities of our team 
of authors, which arises from our multiple disciplinary backgrounds in nursing, politics, rural health services and social work; plus several years of conducting instrumental community participation and researching it, in partnerships with health services managers in settings internationally .

\section{Defining a participation activity using the roadmap}

\section{Figure 1 GOES ABOUT HERE}

The map has five columns. The intention is that users consider the columns to define/characterise a participation initiative that is being planned or evaluated (Figure 1). Following a brief overview of each column below, we give some examples of how the map might be used.

-Column 1: who participates: from our literature analysis, four main ways of conceptualising lay participants are described in the literature, as follows:

Consumer participation: The ACSQHC (2012) standard called 'Partnering with Consumers' mainly features consumer input, and defines consumers as “patients, consumers, families, carers and other support people" (ACSQHC, 2012; p.5). The nature of this grouping suggests consumers as a target group might be best involved in advising on improvements to existing health services because they can comment on their experiences, comparing these with what they want.

Public participation: The more general notion of public participation is not featured in the ACSQHC standards, but does appear in health services literature (e.g. Contandriopoulos, 
2004). In contrast to consumers who are current service users, the public implies consumers, non- and potential consumers, and taxpayers and non-taxpayers. This suggests involvement of people with more general interest, even extending beyond service consumption, to include the role and place of the health service in the locale (Mitton et al., 2009). Inputs from the public might be informed by a range of influences, including previous experiences of participation initiatives and of using services, personal beliefs and values, hearsay and media reports (Nimegeer et al, 2016). Given this, involving a wider public in participation might be most useful for strategic decision-making and prioritysetting.

Community (of place) participation: 'Consultations with communities' are featured in Primary Health Network (PHN) needs assessment guidance (Australian Government, 2015; p.4) and community participation has been reviewed (e.g. Bath \& Wakerman, 2015). There are diverse ways of understanding community (Blackshaw, 2010), but in this context, it is perhaps best defined as inferring a connection between people and place - i.e. of those 'inhabiting a common spatial life-world' (Delanty, 2003; p.55). Community participation is: 'collective actions that harness the socio-cultural affiliations, customs, values and beliefs through social interactions to influence and localise outcomes' (Kenny et al., 2013; p.2). From community development, the belief is that involving local people who have 'culturally or geographically situated knowledges' (Eversole, 2010; p 33) will result in the local context influencing activities.

Community (of interest) participation: There exists a literature on involvement of people with specific experiences such as of mental health issues (e.g. Kidd et al., 2015) or dementia (e.g. Goeman et al., 2016) or Indigenous women (e.g. Aizenberg, 2014). Here, 
something about the shared interests of a group is relevant to proposed activity; for example, a community of people living with mobility problems will have particular experiences of service accessibility.

-Column 2: Intended outcome areas: This column covers reasons for conducting participation.

In guidance documents and literature, multiple reasons for undertaking participation are often bundled together in sentences - potentially leading to confusion about the relationships between different outcome areas - for example, benefits as “...better use of existing health services by being involved in decisions about the development of the services; and change in ... poor health behaviours after being involved in exploring the consequences' (Aizenberg, 2014; p.11). While there is potential for production of multiple outcomes from participation activities, the conflation of reasons to do participation could lead to confused outcome assessment downstream. Based on our consideration of the literature, the reasons for undertaking participation could be viewed as forming a typology, with a continuum from emphasis on service and organisation effects to emphasis on people and society effects. We summarise the reasons for conducting participation (outcome areas), as identified from literature and guidance documents, in Figure 1 and below.

Service improvement: Australian policy proposes participation of consumers produces "services that are more accessible and appropriate for users" (p.6) because "consumers can identify opportunities for improvement" (p.10) (ACSQHC, 2012). Literature proposes that participation benefits design, quality and innovation, of services and health policy (Preston et al, 2010; George et al, 2015; Snijder et al, 2015). Considering public policy more 
generally, Bonetti and Villa (2014) suggest participation is a way of "increasing legitimacy and improving design, governance and implementation of policies" (p.447).

Responsibilisation: One perspective on participation is that it changes citizens' role in health services from consumption only, to a hybrid producer-consumer role. Australian policy states: "people have the right and duty to participate individually and collectively in the planning and implementation of their health care" (ACSQHC, 2012; p.6). Participation initiatives promote citizens' responsibility in health and provide health knowledge, enabling people to contribute to decisions about their own health as well as service planning (Preston et al, 2010). Ultimately, participation makes citizens the co-producers of health (Horne et al., 2013). Holman (2014) says that participation is part of recasting "government as an enabling partner to empowered, active and 'responsibilized' citizens" (p.420).

Health improvement: There are claims of direct impacts on an individual's health from participation because of knowledge (increased health literacy), and consequent behaviour, changes (ACSQHC, 2012; George et al, 2015; Bath \& Wakerman, 2015). Changes can also relate to changed knowledge about how the health system functions (health system literacy) and thus capability to navigate and use it effectively (Preston et al, 2010). Secondary impacts on psychological health and/or wellbeing might be pre-determined by changes to citizen power and confidence, resulting from greater influence in decisionmaking, and from greater social connection through meeting others in participation initiatives (Milton et al., 2011; Attree et al., 2011). 
Citizen influence and community capacity-building: Though infrequently discussed in Australian health policy, participation is promoted in policy studies and community development literature as a way to provide increased opportunities for people from diverse backgrounds to influence issues affecting them (e.g. Head, 2007). Engaging diverse local residents in "sustainable structures, processes, and mechanisms, over which communities have an increased degree of control" (Craig, 2002; pp.125-126) raises the local social status of previously excluded participants, producing empowerment. Bringing citizens together with managers to contribute to decision-making should create a sense of the collective and an 'imagined community’ (Blackshaw, 2010;pp.118-123) around a service, of which the service institution itself is one component. Bringing local residents together to use their capabilities harnesses them as individuals, but also builds a resource greater than the sum of its parts that we might view as 'community capacity'; defined by Taylor (2015) as "the resources a community has that potentially can be used for a specified purpose, and the community's ability to use these for this purpose in changing economic, social and environmental contexts" (p.350).

Democratic participation: A strand of literature in politics and social policy suggests wider democratic effects can be enabled by participation (e.g. Fung, 2003). From a psychology perspective, Campbell and Jovchelovitch (2000) discuss conscientization where, through participation, citizens receive knowledge that equips them to maximise their agency within political structures and institutions. Participation can afford experiences of deliberative decision-making, exposure to research evidence, power sharing and connection to networks of people in influential positions. This can inform people to act in more political ways. 
Overall, there is a dearth of robust evidence in health services research supporting production of effects, given the above reasons for doing participation. Also noteworthy, as with other neoliberal policies, participation may have multi-faceted impacts (Rose \& Miller, 1992); for example, responsibilisation may be burdensome, empowering - or both. Similarly, an instrumental rationale to deploy participation to redesign services could ultimately result in conscientization that leads to political activity.

\section{-Column 3: selecting activities for participation}

The ACSQHS standards (2012) and other writing about PHNs (Meads et al., 2016) outline a list of health services activities in which consumers might participate. This includes governance, planning, strategy, implementation, provision, evaluation, quality improvement, information design and practitioner training. Two literature reviews in health provide similar typologies where participation may be in: diagnosis (identifying and defining problems and priorities); development (of strategies to address priorities); implementation; managing resources; and monitoring and evaluation (George et al, 2015; Snijder et al, 2015).

\section{-Column 4 covers outcome indicators}

An aim of the roadmap is to help practitioners/managers to align participants, activities and desired effects, with appropriate outcomes indicators that can potentially be assessed quantitatively. For example, if service improvement (Column 2) is a goal, then managers should consider the extent to which services planned, implemented, changed or altered and 
whose design involved a participation activity, actually are more accessible, and used, with consequent effects on consumer satisfaction. Similarly, if health improvement is a goal, then changes in health literacy, health behaviours and/or health status could be assessed. In the outcome indicators column, we focus on including 'tangible' concepts that can be examined using existing scales or customised local data collection methods. The point is that change in one or more indicators could be assessed, pre and post-participation. Health literacy, health status and wellbeing have standardised measurement scales. Social concepts can also be assessed; for example, social networks, defined as "connections among people, organizations, political entities, and/or other units" (Valente, 2010 p.3) can be subject to social network analysis, and there are tools for measuring social cohesion (a measure of integration and social stability including trust, sense of belonging, and willingness to help others (Chan et al. 2006: 290)), see Acket et al. (2011) and empowerment (Ibrahim \& Alkire, 2007). Column 4 is intended to approximately align with Column 2.

Offering outcome indicators that can be assessed makes their examination seem straightforward, but there are challenges. Confusion can arise from considering changes caused due to outputs from participation (i.e. new service designs that lead to new services); and, on the other hand, differences caused by effects from the process of participating (eg. changes in knowledge and networks). In either of these situations, primary changes could lead to secondary effects such as changes in health. As examples: a new service (output) could make healthcare more accessible, enhancing health; or feelings of empowerment realised through having increased influence on decision-making (process) could lead to enhanced wellbeing. For outcome assessment, a significant issue is for managers to focus on aligning the outcomes to be examined with the reasons for 
undertaking participation. Changes in indicators, over time, can be examined and assessment conducted at individual and/or community level(s), as we have noted in Figure 1.

To date, there has been little robust quantitative evidence of outcomes assessment from participation (Milton et al., 2011; George et al., 2015). This could be due to unclear goals for participation activities and the interdependence of effects caused by a participatory process and/or its outputs. The relationship between individual benefits and broader community benefits is also under-researched.

\section{-Column 5 covers contextual factors that influence participation initiatives}

Certain factors influence how participatory processes unfold and resulting outcomes. These are important because managers need to be mindful of their effects as they plan, roll-out or evaluate participation activities. While health guidance contains warnings that managers should adapt their participation activities for context, which contextual factors might be influential in 'real-life' participation activities, has received little focused study. Abelson et al. (2007) set out to examine the role of context in a deliberative participation 'experiment'. However, the experimental conditions were specific and findings potentially lack transferability as community participants were selected and the participation activity consisted of single workshops. The researchers concluded that the method and topics explored influenced what happened and found little evidence of differing locale or community capacity effect on outputs. In our current (2014-17) Rural Engaging Communities in Oral Health (Rural ECOH) study of processes and outputs of community participation in six different rural Australian communities 
[ruralecoh2.files.wordpress.com/2015/05/rural-ecoh-brochure.pdf], emerging findings show a set of contextual factors that influenced differences between communities of similar size $(<12,000$ people) and shared characteristics of rural socio-economic disadvantage and distance from service centres. We include a set of contextual factors in Column 5 of the Map, but suggest the influence of context on participation activities and outcomes is an area ripe for fine-grained study.

Participant motivations: In Rural ECOH, we found that participants tended to be motivated by: wanting to achieve a specific outcome for their community or organisation (e.g. water fluoridation or a fluoride varnishing program for children's teeth); perceptions that they could contribute useful information; or a role where they could affect service change (e.g. school staff that incorporated oral health education and tooth-brushing). Individuals' reasons for participating appeared to influence the priorities and service designs produced in co-design initiatives. Our findings align with other studies highlighting that individuals have particular motivations for participating and that this means not all citizens are amenable to participation (Wandersman et al., 1987; Froding et al, 2011).

Location: In Rural ECOH we found that distance from service centres was significant to participants' initial motivations to participate. Once engaged in participation activities, location and local services already available in the setting influenced the new services that people designed; for example - in one community - teachers, school nurses and council staff suggested that oral health education could be added within time set aside for school student immunisations. 
Participation method: As with Abelson et al. (2007), we found that elements of the participation methodology such as times and venues for the public workshops affected attendance. In a Scottish study, community participants discussed dislike of public events and preference for providing input anonymously and incrementally commenting on designs. Such findings suggest the physical and social spaces of participation are significant (Renedo \& Marston, 2014).

Topic: While Abelson et al. (2007) found topic affected participation discussion and consensus outputs, in Rural ECOH there were several suggestions that there was low interest in oral health which deterred general community members, other than service practitioners, from participating. There are suggestions therefore that an engaging topic is important for gaining widest participation.

Facilitators: The influence of people who facilitate participation in health has received limited consideration. In a rural Scottish study, Nimegeer (2012) concluded that her Canadian rural origins and relative youth influenced participant engagement in an initiative she facilitated. In Rural ECOH, facilitators attended local events to build trust and credibility. Their backgrounds in public health and education likely impacted on outcomes of a participatory process.

Sponsors: Leadership from a credible organisation may encourage involvement.

Knowledge about the resources, power and role of sponsoring organisations were found important factors in motivating public sector practitioners' participation in Rural ECOH. Perceived institutional credibility (Swapan, 2016) and buy-in of high level policymakers 
(de Vente et al., 2016) have been shown to increase stakeholder motivation to participate in other policy areas.

\section{Using the map}

Below we give two examples of how a manager might use the map (Figure 1).

Managers A and B are both required to introduce participation. Using the map, Manager A decides she wants to apply participation to improve outpatient services while Manager B decides he would like to use participation so that local people become more responsible users of out of hours services (i.e. make appropriate demand).

Guided by considering dimensions/columns in the map, Manager A decides to focus on consumers, involve them in planning to gain service improvement and that she will assess changes to outcome indicators on service quality and safety, costs and community support. Meanwhile, Manager B decides to involve the community, engage local people in designing new information on using the Out of Hours Service. He thinks this might change their responsible use of services and it could have health improvement effects. He decides he will examine data on service use longitudinally to see if there are any effects and will carry out a small community survey to understand any changes in health knowledge or behaviour.

In both cases, using the map, the managers are alerted to a range of contextual factors that could influence what happens.

\section{Conclusion}


Healthcare managers are increasingly required to involve lay people in aspects of health services. We suggest that the combination of assistance available - bulky academic literature and sketchy policy - can be confusing. Academic literature often focuses on challenges of different types of participation for different reasons, while policy literature may portray participation as deceptively practical and panacea-like. There is a risk that discussing participation only from within particular theoretical and/or disciplinary perspectives means that we never achieve a view across these perspectives, which is crucial for practitioners who need to plan and design activities under time and resource pressure.

We anticipate the map will help with:

- Defining what to do: managers can work across columns $1,2,3$ and 4 to decide who to invite, what to involve them in, what should change and how to assess that. They can also understand what might influence process and outcomes (column 5).

- Evaluation: the map can be used as a frame to help analyse what has happened in a participation initiative.

Our map is original in providing clarity about key dimensions of, and perspectives on, participation as it pertains to an instrumental exercise undertaken in contemporary health services. In doing so, it inevitably has the flaws of a constructed 'Ideal Type'. Within these choices there are clearly affinities (for example: consumer-responsibilisaton-appropriate service use) and we do not wish to imply that this is a 'pick-and-mix menu' for managers. However, in a field where practitioners often bemoan the normative focus of frameworks such as Arnstein's famous 'ladder of participation', there is value in supporting managers 
to navigate the complexity of participation and to compare the choices that can be made

when designing participation initiatives.

\section{Competing Interests}

There are no competing interests.

Citizen participation in health service co-production
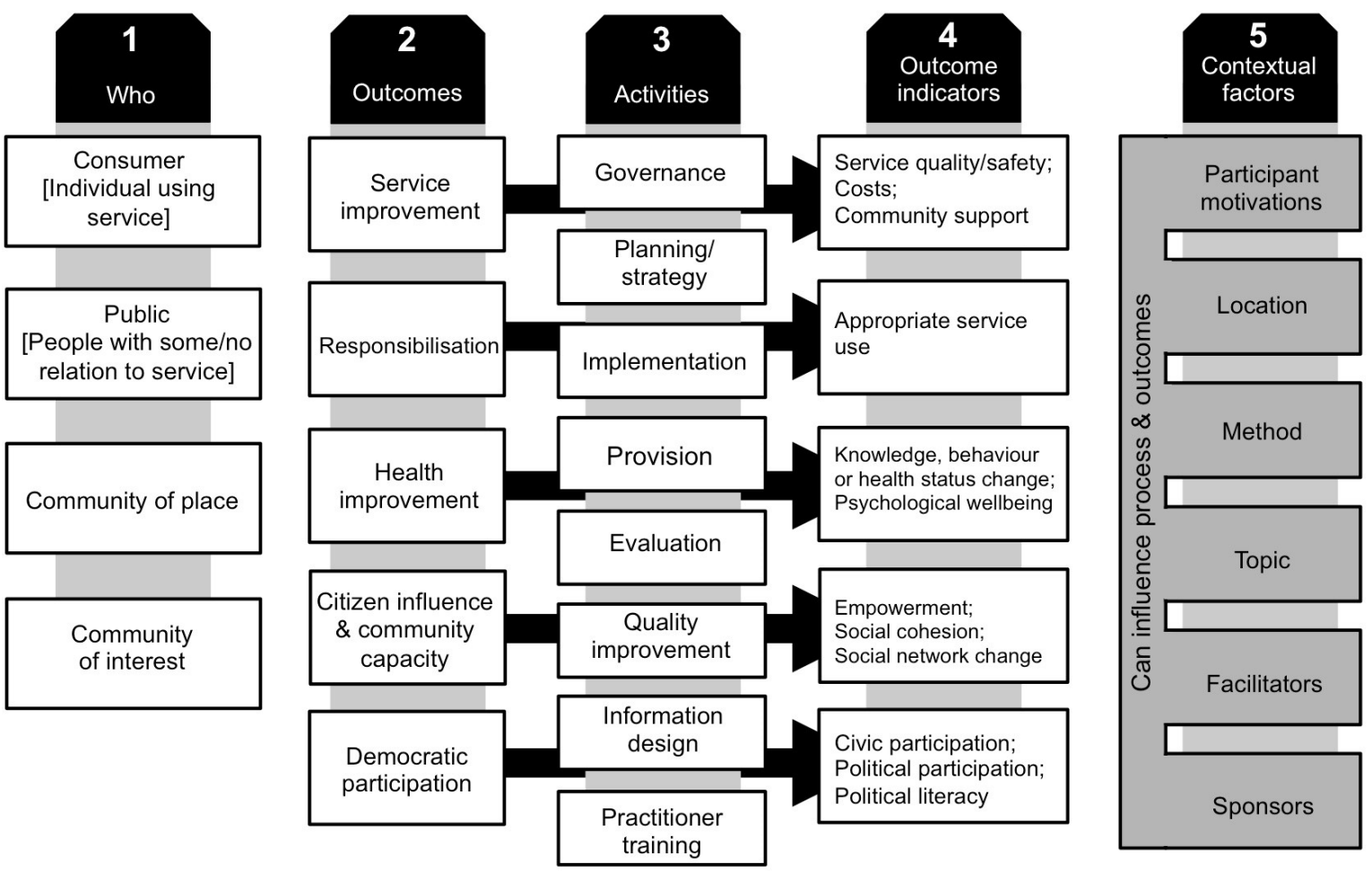


\section{References}

Abelson J, Eyles J, Martin E, Mackean G (2007) Examining the role of context in the implementation of a deliberative public participation experiment: results from a Canadian comparative study. Social Science \& Medicine, 64, 2115-2128.

Acket S, Borsenberger M, Dickes P, Sarracino F (2011) Measuring and validating social cohesion: a bottom-up approach. Luxembourg: OECD.

ACSQHC (2012) 'National Safety and Quality Health Service (NSQHS) Standards'. (ACSQHC: Sydney).

Aizenberg L (2014) Facilitating Indigenous women's community participation in healthcare. Health Sociology Review, 23,2, 91-101.

Arnstein S (1969) A ladder of citizen participation. Journal of the American Institute of Planners, 35, 216-224

Attree P, French B, Milton B, Povall S, Whitehead M, Popay J (2011) The experience of community engagement for individuals. Health \& Social Care in the Community, 19, 3, 250-60.

Australian Government (2015) PHN Commissioning: needs assessment guide. Canberra: Department of Health.

Bath J, Wakerman, J (2013) Impact of community participation in primary health care: what is the evidence? Australian Journal of Primary Health, 21, 1, 2-8.

Blackshaw T (2010) Key concepts in community studies. London; Sage.

Bonetti M, Villa M (2014) In the shadow of legalism: understanding community participation in an overly bureaucratic context. Critical Policy Studies, 8,4, 447-64.

Campbell C, Jovchelovitch S (2000) Health, community and development: towards a social psychology of participation. Journal of Community and Applied Social Psychology, 10,4, 255-270.

Chan J, To H, Chan, E. (2006) Reconsidering social cohesion: developing a definition and analytical framework for empirical research, Social Indicators Research, 75, 273-302.

Contandriopoulos D (2004) A sociological perspective on public participation in health care. Social Science \& Medicine, 58, 2, 321-330.

Craig G (2002) Towards the measurement of empowerment. Journal of the Community Development Society, 33,1, 124-46. 
De Vente J, Reed M, Valente S, Newig J (2016) How does the context and design of participatory decision making processes affect their outcomes? Ecology \& Society, 21, 2, 24 DOI: 10.5751/ES-08053-210224

Delanty G (2003) Community. London; Routledge.

Eversole R (2012) Remaking participation: Challenges for community development practice. Community Development Journal, 47, 1,29-41.

Froding K, Elander I, Eriksson C (2011) Neighbourhood development and public health initiatives: who participates? Health Promotion International, 27, 1, 102-116.

Fung, A. (2003) Empowered participation: reinventing urban democracy. Berkeley: University of California Press.

George AS, Mehra V, Scott K, Sriram V (2015) Community participation in health systems research: a systematic review assessing the state of research, the nature of interventions involved and the features of engagement with communities. PLOSOne, 10, 10: e0141091.

Goeman D, King J, Koch S. (2016) Development of a model of dementia support and pathway for culturally and linguistically diverse communities using co-creation and participatory action research. BMJ Open, 6:e013064. doi:10.1136/bmjopen-2016- 013064

Head B (2007) Community engagement: participation on whose terms? Australian Journal of Political Science, 42, 3, 441-454.

Holman DV (2014) The relational bent of community participation. Community Development Journal, 50, 3, 418-432.

Horne M, Khan H, Corrigan P (2013) People powered health: health for people, by people and with people. London: NESTA.

Ibrahim S, Alkire S (2007) Agency and empowerment: a proposal for internationally comparable indicators. Oxford: Oxford Poverty and Human Development Initiative. [http://peaceworkspartners.org/ophi/OPHI_CD_v1.4/OPHI/Missing\%20Dimensions\%20Fr ench_files/Ibrahim_Alkire_Empowerment_FINAL_2.pdf]

Keleher H (2015) Partnerships and collaborative advantage in primary care reform. Deeble Institute Evidence brief no.13. [ahha.asn.au/sites/default/files/docs/policyissue/deeble_evidence_brief_no_13_partnerships_and_collaborative_advantage_in_primar y_care.pdf]

Kenny A, Hyett N, Sawtell J, Dickson-Swift V, Farmer J, O'Meara P (2013) Community participation in rural health: a scoping review. BMC Health Services Research 13:64 DOI: 10.1186/1472-6963-13-64 
Kidd S, Kenny A, McKinstry C (2015) The meaning of recovery in a regional mental health service: an action research study. Journal of Advanced Nursing, 71,1, 181-92

Llewellyn-Jones L, Harvey D (2005) The development of a Health Promotion Community Participation Framework [www.publish.csiro.au/PY/pdf/PY05032].

McEvoy R, MacFarlane A (2013) Community participation in primary care in Ireland: the need for implementation research. Primary Health Care Research \& Development, 14, 2 , 126-139.

Meads G, Russell G, Lees A (2016) Community governance in primary health care: towards an international Ideal Type. International Journal of Health Planning \& Management DOI: 10.1002/hpm.2360

Milton B, Attree P, French B, Povall S, Whitehead M, Popay J (2011) The impact of community engagement on health and social outcomes. Community Development Journal, 47, 3, 316-334.

Mitton C, Smith N, Peacock S, Evoyd B, Abelson J (2009) Public participation in health care priority setting: a scoping review. Health Policy, 91, 219-228.

Nimegeer A (2012) 'Considering community engagement for remote and rural healthcare design in Scotland: exploring the journey from rhetoric to reality.' University of Aberdeen $\mathrm{PhD}$ thesis.

Nimegeer A, Farmer J, Munoz S-A, Currie M (2016) Community participation for rural healthcare design: description and critique of a method. Health \& Social Care in the Community. 24(2), 175-183.

Preston R, Waugh H, Larkins S, Taylor J (2010) Community participation in rural primary health care: intervention or approach? Australian Journal of Primary Health, 16, 1, 4-16.

Quick KS, Feldman MS (2011) Distinguishing participation and inclusion. Journal of Planning Education and Research, 31, 3, 272-90.

Renedo A, Marston C (2014) Spaces for Citizen Involvement in Healthcare: An Ethnographic Study. Sociology, August 26, 2016 0: 0038038516664683v138038516664683

Rifkin S (2014) Examining the links between community participation and health outcomes: a review of the literature. Health Policy and Planning, 29(Suppl.2), ii98-iilo6.

Rose N, Miller P (1992) Political power beyond the state: problematics of government. British Journal of Sociology, 43, 2, 173-205. 
Snijder M, Shakeshaft A, Wagemakers A, Stephens A, Calabria B (2015) A systematic review of Australian Indigenous community development projects. BMC Public Health, 15, 1154 DOI 10.1186/s12889-015-2514-7.

Stewart E (2016) Publics and their health systems: rethinking participation. London: Palgrave MacMillan.

Swapan MSH (2016) Who participates and who doesn't? Adapting community participation model for developing countries. Cities, 53, 70-77.

Taylor J (2015) 'Working with communities'. (Oxford University Press: Oxford).

Valente TW (2010) Social networks and health: models, methods and applications. Oxford: Oxford University Press.

Wandersman A, Florin P, Friedmann R, Meier R (1987) Who participates, who does not, and why? An analysis of voluntary neighbourhood organizations in the United States and Israel. Sociological Forum, 2, 3, 534-555. 